\title{
Pediatric head injury: a pain for the emergency physician?
}

\section{Shu-Ling Chong', Khai Pin Lee', Jan Hau Lee², Gene Yong-Kwang Ong', Marcus Eng Hock Ong ${ }^{3}$}

'Department of Emergency Medicine, KK Women's and Children's Hospital, Singapore

${ }^{2}$ Children's Intensive Care Unit, KK Women's and Children's Hospital, Singapore

${ }^{3}$ Department of Emergency Medicine, Singapore General Hospital, Singapore

The prompt diagnosis and initial management of pediatric traumatic brain injury poses many challenges to the emergency department (ED) physician. In this review, we aim to appraise the literature on specific management issues faced in the ED, specifically: indications for neuroimaging, choice of sedatives, applicability of hyperventilation, utility of hyperosmolar agents, prophylactic anti-epileptics, and effect of hypothermia in traumatic brain injury. A comprehensive literature search of PubMed and Embase was performed in each specific area of focus corresponding to the relevant questions. The majority of the head injured patients presenting to the $E D$ are mild and can be observed. Clinical prediction rules assist the ED physician in deciding if neuroimaging is warranted. In cases of major head injury, prompt airway control and careful use of sedation are necessary to minimize the chance of hypoxia, while avoiding hyperventilation. Hyperosmolar agents should be started in these cases and normothermia maintained. The majority of the evidence is derived from adult studies, and most treatment modalities are still controversial. Recent multicenter trials have highlighted the need to establish common platforms for further collaboration.

Keywords Pediatrics; Child; Craniocerebral trauma; Brain injuries
eISSN: 2383-4625

Received: 23 December 2014

Revised: 10 January 2015

Accepted: 26 January 2015

Correspondence to: Shu-Ling Chong Department of Emergency Medicine, KK Women's and Children's Hospital, 100, Bukit Timah Road, Singapore 229899

E-mail: Chong.Shu-Ling@kkh.com.sg

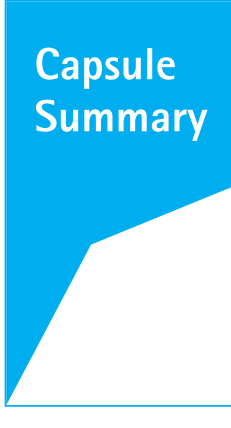

What is already known

Children with head injuries present with varied complaints and a wide spectrum of severity. The ED physician is frequently challenged to make prompt yet important decisions in the early hours after the injury.

What is new in the current study

In this clinical review, the authors appraise current literature in the diagnosis and management of pediatric head injury, from the ED physician's perspective.

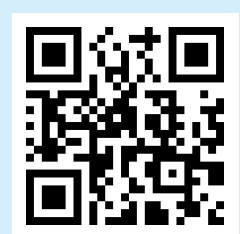

How to cite this article:

Chong SL, Lee KP, Lee JH, Ong GY, Ong ME. Pediatric head injury: a pain for the emergency physician? Clin Exp Emerg Med 2015;2(1):1-8.

This is an Open Access article distributed under the terms of the Creative Commons Attribution Non-Commercial License (http:// creativecommons.org/licenses/by-nc/3.0/). 


\section{INTRODUCTION}

Children with traumatic brain injury (TBI) are at risk of death and permanent neurological disability. Children are especially vulnerable to TBI due to the softer pliable skull' and susceptibility to accelerating and decelerating forces. Infants present mainly after falls, while older children suffer from transportation accidents and sports-related injuries. ${ }^{2}$ In the absence of a clear mechanism of injury, the physician must also consider inflicted TBI.

When faced with a head-injured child, rapid and accurate diagnosis may be hindered by the variable presentation of the pediatric patient. Early decisions on the need for neuroimaging, immediate resuscitation, and prompt treatment of raised intracranial pressure (ICP) are pivotal for good patient outcomes.

In this review, we aim to critically appraise the current literature on diagnosis and initial management of pediatric head injury. Specifically, this narrative review is meant to be emergency department (ED)-centric, and focuses on the dilemmas faced in the management of paediatric TBI. The following areas are the focus of this review: indications for neuroimaging, choice of sedatives, applicability of hyperventilation, utility of hyperosmolar agents, prophylactic anti-epileptics, and effect of hypothermia in pediatric TBI.

\section{MATERIALS AND METHODS}

A comprehensive literature search was performed in each specific area of focus corresponding to the relevant questions: PubMed was searched using the MeSH search terms: brain injuries; child; neuroimaging; hypnotics and sedation; hypocapnia; hypertonic solution, saline; anticonvulsants and hypothermia. Embase was also searched using the terms: traumatic brain injury; child; neuroimaging; hyperventilation; hyperosmolar; anticonvulsive agent and hypothermia. Original and review articles were identified and selected based on the relevance to this review, and references were hand searched. The search was not limited by year of publication. Articles that were not written in English, and case reports were excluded. Relevant references from the adult TBI literature are included in this paper, due to the paucity of pediatric-specific literature regarding certain treatment modalities (Fig. 1).

\section{RESULTS AND DISCUSSION}

Which head-injured child requires a computed tomography for brain? Indications for neuroimaging

Children with head injuries present with varied complaints. It has always been a challenge for the ED physician to decide which head injured child requires urgent neuroimaging. While the fast-

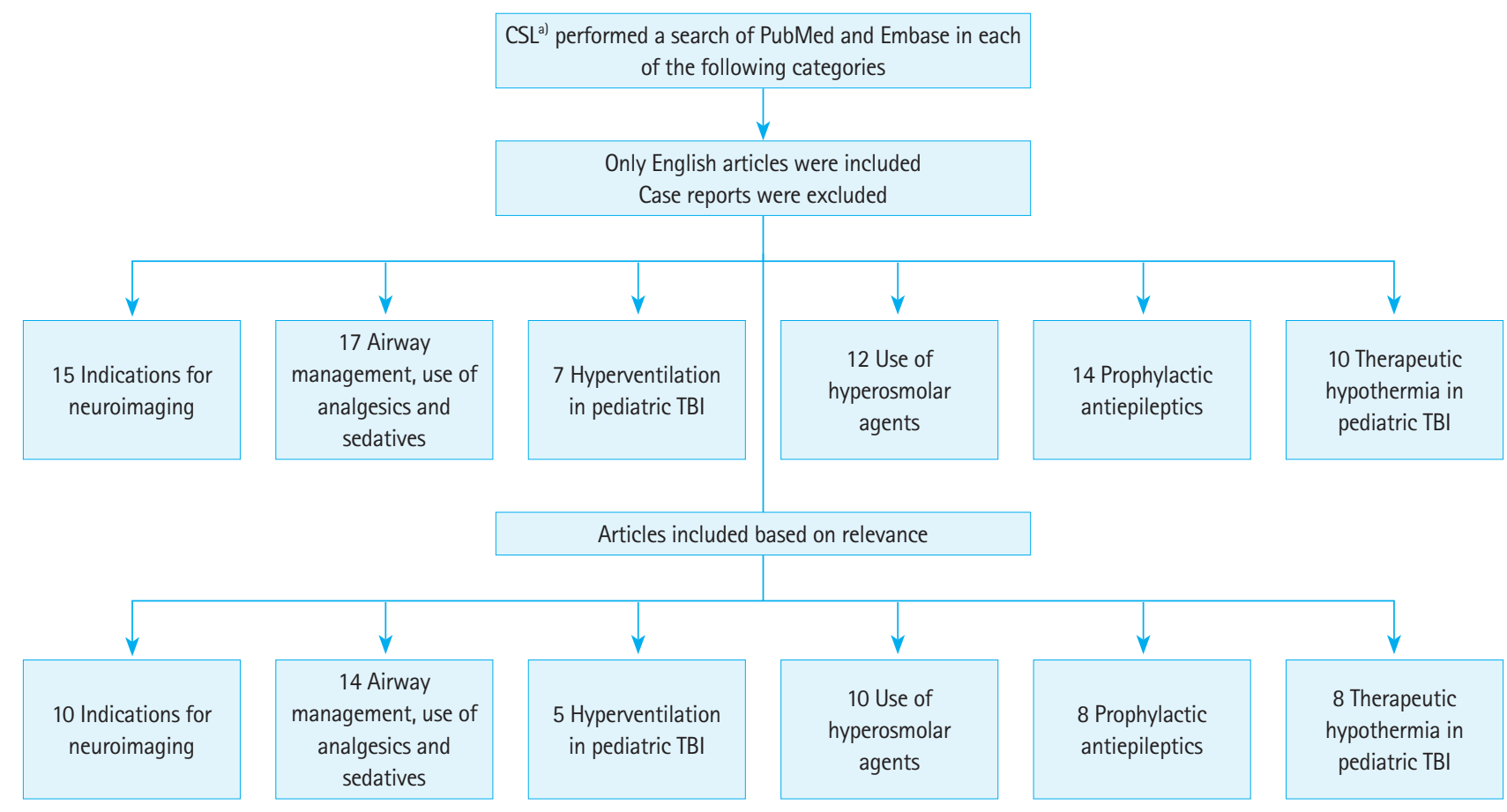

Fig. 1. Flow diagram of literature selection process. TBI, traumatic brain injury. ${ }^{\text {a) }} \mathrm{CSL}$ (Chong Shu-Ling), first author, performed the literature search. The other authors reviewed the relevance of the literature included and the concurrence of recommendations in each area. 
est way to exclude an intracranial bleed is to perform a computed tomography (CT) scan of the brain, but the resultant radiation is significant in children. A large data linkage study recently published showed that, after accounting for age, sex and the year of birth, the cancer incidence is 24\% greater for children and adolescents exposed to CT scans compared to unexposed individuals. ${ }^{3}$ Interestingly, for brain cancer and all cancers combined, the incidence rate ratio was greater at younger ages. The region being exposed to radiation is also relevant, with brain CTs being significantly associated with brain tumors. ${ }^{4}$

Clinical prediction tools (CHALICE, PECARN, and CATCH) have been derived to guide the ED physician on which child should be imaged. ${ }^{5-7}$ These clinical prediction rules assist the ED physician in risk stratifying patients at risk for TBI. The PECARN rule was adequately powered by a large study population $(n=42,412)$ in which the rule was not only derived but also validated. ${ }^{6}$ Importantly, the study population comprised a significant number of preverbal children ( $<2$ years), among whom complaints are usually vague and to whom the risk of radiation is of particular concern. A recent prospective cohort study demonstrated that of the 3 rules, PECARN performed with the best sensitivity. ${ }^{8}$ Still, others have proposed that a period of monitoring should be instituted in most cases, as that was shown to lead to more discretionary neuroimaging. ${ }^{9}$ After adjusting for patient age, time from injury and physician type, it was demonstrated that every hour of ED observation time was associated with a decrease in $\mathrm{CT}$ rate for children across all risk groups. ${ }^{10}$ In this study, there was no delay to the diagnosis of significant TBI. In a survey among parents of children 2 years or older presenting to the ED with the presenting complaint of head injury, the parents were divided in opinion, with a majority (57\%) preferring observation over immediate CT. ${ }^{11}$ The performance of the above 3 rules are currently being compared and validated in an ongoing prospective study by a large research network. ${ }^{12}$ In the meantime, ED physicians need to weigh the advantage of prompt diagnosis against the disadvantage of radiation exposure.

\section{Airway management and the use of analgesics and sedatives}

A patient with a presenting Glasgow Coma Scale $\leq 8$ (or one that is fluctuating), is at risk of losing airway protection. At the ED, timely endotracheal intubation and effective ventilation prevents one of the most important causes of secondary injury to the brain: hypoxemia. ${ }^{13}$ This also allows for the management of raised ICP.

The use of sedatives facilitates the ability to maintain a definitive airway and perform invasive interventions. They mitigate the effect of stress and pain, and also have anti-seizure and anti-eme- tic properties, ${ }_{1}^{14}$ and attenuate the rise in ICP during interventions. Hypotension must be avoided during induction because of the resultant reduction in cerebral perfusion pressure (CPP) and consequently secondary injury to the brain. ${ }^{13,15}$

Because of the paucity of data in this area, we utilized pertinent adult data to discuss some of the commonly used sedative drugs available for use in the ED setting for a child with TBI. A systematic review of 13 randomized controlled trials among adults with severe TBI (Glasgow Coma Scale $\leq 8$ ) did not demonstrate the superiority of any sedative agent on mortality or neurologic outcomes, nor on ICP and CPP. ${ }^{16}$

Etomidate, favored in the setting of hemodynamic instability, has been associated with reduced ICP and improvement in CPP among pediatric patients with severe TBI. ${ }^{17}$ When using etomidate, the physician must however bear in mind the possibility of adrenal suppression. A single bolus dose for induction has been demonstrated to reduce the synthesis of cortisol, and increase the risk for relative adrenocortical insufficiency. ${ }^{18}$

The use of propofol in adults has shown favorable effects on the cerebral blood flow and ICP. ${ }^{19,20}$ However, propofol can cause a drop in the mean arterial pressure and CPP especially in unstable hypovolemic patients. Concerns have arisen due to the propofol infusion syndrome, particularly in children-as defined by acute bradycardia, enlarged or fatty liver, metabolic acidosis, rhabdomyolysis or myoglobinuria. ${ }^{21}$ Brugada-like electrocardiogram changes with potential malignant arrhythmias have also been reported. ${ }^{22}$

Benzodiazepines, easily available and frequently used in many $E D s$, can provide amnesia, anxiolysis and anti-convulsant effects. ${ }^{15}$ However, besides the risk of hypotension, benzodiazepines also cause significant respiratory depression, and the accumulation of metabolites may prolong the sedation, affecting subsequent neurological assessment. ${ }^{15}$

Ketamine was previously believed to worsen raised ICP. However, key studies have shown otherwise. When compared to other sedative agents, ketamine does not decrease mean arterial pressure and therefore maintains $\mathrm{CPP}^{23,24}$ In a small prospective series, Bar-Joseph et al..$^{25}$ showed that among 30 children with raised ICP, a single dose of ketamine ( 1 to $1.5 \mathrm{mg} / \mathrm{kg}$ ) was able to prevent further increases in ICP during stressful procedures, as well as reduce ICP among those with refractory intracranial hypertension. This study, however, did not have any control for confounders. A more recent systematic review of 10 adult randomized and non-randomized prospective studies reported no significant differences in CPP, or patient-centered outcomes (mortality, intensive care unit length of stay, or neurologic outcomes) with the use of ketamine in the setting of TBI. ${ }^{26}$ 
We recommend that among TBI patients with stable hemodynamic status and the absence of known adrenal insufficiency, etomidate may be used. If benzodiazepines are used, strict blood pressure monitoring must be performed. For TBI patients who have hypotension or unstable hemodynamic status, ketamine can be used.

\section{Hyperventilation in pediatric traumatic brain injury}

Hyperventilation produces hypocapnia-induced cerebral vasoconstriction, thereby reducing cerebral blood flow and blood volume. It decreases cerebral oxygenation and may induce brain ischemia. ${ }^{27}$ Ischemic thresholds are exceeded in a dose-dependent relationship with increasingly aggressive hyperventilation. ${ }^{28}$ Curry et al. ${ }^{29}$ showed in a large retrospective cohort pediatric study that with increasing episodes of severe hypocarbia $\left(\mathrm{P}_{\mathrm{a}} \mathrm{CO}_{2}<30 \mathrm{mmHg}\right)$, the mortality-adjusted odds ratio (OR) increased. It has since been recommended that prophylactic severe hyperventilation to $\mathrm{P}_{2} \mathrm{CO}_{2}$ $<30 \mathrm{mmHg}$ should be avoided in the initial 48 hours after injury. ${ }^{30}$

Another retrospective study performed among children with severe TBI showed that patients with admission $\mathrm{P}_{2} \mathrm{CO}_{2}$ between 36 to $45 \mathrm{mmHg}$ had better discharge survival rate (adjusted OR 5.47 for discharge survival) compared to those with admission hypocarbia $\left(\mathrm{P}_{2} \mathrm{CO}_{2} \leq 35 \mathrm{mmHg}\right)$ and hypercarbia $\left(\mathrm{P}_{\mathrm{a}} \mathrm{CO}_{2} \geq 46 \mathrm{mmHg}\right){ }^{31}$

In cases of refractory intracranial hypertension, if hyperventilation is to be considered, then advanced neuromonitoring for evaluation of cerebral ischemia should be instituted. ${ }^{30}$ In the ED, hyperventilation should not be performed routinely for head injured patients (level III evidence).

\section{The use of hyperosmolar agents}

Mannitol previously dominated in the use of hyperosmolar therapy. While useful to reduce $I C P_{1}^{32}$ the effect on mortality and functional outcomes has been equivocal when compared to placebo. ${ }^{33}$ Concerns have surrounded the adverse effects of mannitol causing hypovolemia due to diuresis and the association with renal failure. $^{34}$

Hypertonic saline has gained increasing favor recently. ${ }^{35}$ It treats hyponatremia (which can result from cerebral salt wasting, syndrome of inappropriate anti-diuretic hormone and sodium losses from cerebral spinal fluid drainage). ${ }^{30}$ Hypertonic saline increases the mean arterial pressure, therefore avoiding the secondary insult of hypotension on the injured brain. ${ }^{36}$ By raising the serum osmolality, it reduces the influx of water into the extracellular spaces, and reduces the resultant cerebral edema. It was shown in a small prospective observational study done among children ${ }^{37}$ to reduce the ICP spikes and increase the CPP. Possible side effects include a rebound in the ICP, central pontine myelinolysis, renal impairment and natriuresis. ${ }^{38}$

In two randomized controlled trials, the use of hypertonic saline was associated with reduced need for additional interventions to treat the raised ICP. ${ }^{39,40}$ Simma et al. ${ }^{40}$ reported fewer interventions, and shorter duration of mechanical ventilation among children who received hypertonic saline compared to those who received lactated Ringer's solution, but there was no difference in the survival rates between the groups. Among 68 children studied retrospectively, Peterson et al. ${ }^{41}$ found that the use of hypertonic saline resulted in a survival rate that was higher than expected based on trauma and Injury Severity Score. Moreover, none of the patients in that cohort developed central pontine myelinolysis or rebound increase in ICP. Based on current medical literature, hypertonic saline is one of the few therapies with level II evidence and the recommended dose of 3\% hypertonic saline ranges from 6.5 to $10 \mathrm{~mL} / \mathrm{kg} .^{30} \mathrm{~A}$ continuous infusion between 0.1 to $1.0 \mathrm{~mL} /$ $\mathrm{kg} / \mathrm{hr}$ may be considered subsequently. ${ }^{30}$

\section{Prophylactic anti-epileptics in children with head injury} Post traumatic seizures (PTS) are classified as early PTS if they occur within 7 days of injury. ${ }^{2}$ The risk factors for PTS include: young age, severe injury, presence of intraparenchymal hemorrhage ${ }^{42}$ and non-accidental trauma. ${ }^{43}$ Seizures among critically ill children may be subtle and challenging to diagnose. ${ }^{44}$ In a randomized double-blinded study of 404 adults, Temkin et al. ${ }^{45}$ reported that there was a statistically significant risk reduction in the incidence of early PTS in head-injured patients, with the use of phenytoin (risk ratio, $0.27 ; 95 \%$ confidence interval [Cl], 0.12 to 0.62 ).

Specific to the pediatric population, Young et al ${ }^{46}$ recruited 102 children less than 16 years old in a randomized, double-blinded and placebo-controlled study which showed no reduction in rate of PTS within 48 hours of injury despite the use of phenytoin. However, this study had very low seizure rate $(6 \%)$ and a marked decrease in enrolment without waiver of consent. There was also a significant number that was lost to follow up. In contrast, a more recent retrospective observational study of children $(n=275)$ with moderate to severe TBI found the use of anti-epileptic drugs (fosphenytoin or phenytoin, or phenobarbital) to be protective against the development of early post-traumatic seizures (OR, 0.2; $95 \%$ $\mathrm{Cl}, 0.07$ to 0.5$).{ }^{47}$ In this study, the rate of early post-traumatic seizures was $12 \%$.

Besides phenytoin, the use of levetiracetam has been reported in a phase 2 study for the prevention of posttraumatic epilepsy. ${ }^{48}$ A small cohort was followed up for 2 years, ${ }^{49}$ and the authors report that it is safe and feasible for further prospective studies.

Until further evidence is available, the utility of anti-epileptic prophylaxis in children remains controversial. We feel that the fi- 
Table 1. Summary recommendation table

\begin{tabular}{|c|c|c|}
\hline Area of study & Recommendations & Comments \\
\hline Indications for neuroimaging & $\begin{array}{l}\text { Physicians can use current clinical prediction tools: } \text { PECARN, }^{6} \\
\mathrm{CHALICE}_{1}^{5} \text { or } \mathrm{CATCH}^{7} \text { to aid in their decision-making }\end{array}$ & $\begin{array}{l}\text { PECARN }{ }^{6} \text { has been shown to perform with highest sensitivity. A } \\
\text { period of observation is recommended in most patients with } \\
\text { Glasgow Coma Scale } 14-15^{10}\end{array}$ \\
\hline Choice of sedatives & $\begin{array}{l}\text { Unstable hemodynamics: consider ketamine } \\
\text { Stable hemodynamics: consider ketamine or benzodiazepines. } \\
\text { Etomidate can be considered in the absence of known adrenal } \\
\text { insufficiency. }\end{array}$ & Hypotension should be avoided during induction \\
\hline Applicability of hyperventilation & Severe hyperventilation to $\mathrm{P}_{\mathrm{a}} \mathrm{CO}_{2}<30 \mathrm{mmHg}$ should be avoided & $\begin{array}{l}\text { Increasingly aggressive hyperventilation may induce ischemia in } \\
\text { a dose-dependent relationship }{ }^{28}\end{array}$ \\
\hline Utility of hyperosmolar agents & Use of $3 \%$ hypertonic saline is recommended & $\begin{array}{l}\text { Use of } 3 \% \text { hypertonic saline is likely to reduce the need for oth- } \\
\text { er interventions to treat raised intracranial pressure }{ }^{39,40}\end{array}$ \\
\hline Prophylactic anti-epileptics & $\begin{array}{l}\text { There is no conclusive evidence to recommend the routine use of } \\
\text { prophylactic anti-epileptics }\end{array}$ & $\begin{array}{l}\text { Phenytoin should be started in the event of clinical suspicion of } \\
\text { seizure activity }\end{array}$ \\
\hline Hypothermia in traumatic brain injury & Normothermia is recommended & $\begin{array}{l}\text { Hypothermia is associated with hypotension and unfavourable } \\
\text { outcomes }^{53,55,56} \\
\text { Hypothermia also affects drug elimination }{ }^{57}\end{array}$ \\
\hline
\end{tabular}

nal decision depends on the physician's discretion, but would recommend starting the anti-epileptic if there is a clinical suspicion of possible seizure activity.

\section{Therapeutic hypothermia in pediatric traumatic brain injury}

Several small studies had demonstrated a positive effect of cooling on intracranial hypertension in TBI patients. ${ }^{50,51}$ However, in a meta-analysis that included randomized controlled trials in pediatric TBI comparing hypothermia groups versus normothermia, the authors found a tendency towards increased risk of cardiac arrhythmias (relative risk, 2.57; 95\% Cl, 1.01 to 6.54) and death (relative risk, $1.73 ; 95 \% \mathrm{Cl}, 1.06$ to 2.84$]{ }^{52} \mathrm{~A}$ significant contribution to this pooled effect came from the Hutchison study ${ }^{53}$ in which 225 children were randomized to either cooling to $32^{\circ} \mathrm{C}$ to $33^{\circ} \mathrm{C}$ within 8 hours of injury or normothermia. They found an unfavorable outcome at 6 months with more deaths, more hypotension and more use of vasoactive agents in the hypothermia group, especially during the rewarming period. Concerns were raised regarding the use of marked hyperventilation $\left(\mathrm{P}_{\mathrm{a}} \mathrm{CO}_{2}<30\right.$ $\mathrm{mmHg}$ ) as part of the standard protocol, as well as the speed of rewarming.

In the closely followed Cool Kids Trial, the phase II study ${ }^{54}$ showed that the ICP was significantly reduced in the initial 24 hours after TBI. In the follow up phase III trial, patients were enrolled within 6 hours of injury and randomly allocated to either hypothermia $32^{\circ} \mathrm{C}$ to $33^{\circ} \mathrm{C}$ for 48 to 72 hours or normothermia. ${ }^{55}$ No difference was detected for mortality (15\% in hypothermia group versus $5 \%$ in normothermia group, $\mathrm{P}=0.15$ ) nor functional outcomes and the study was terminated early for futility after an interim data analysis. ${ }^{55} \mathrm{~A}$ later meta-analysis suggested an in- creased risk of death with hypothermia therapy compared to the normothermia group, although not statistically significant. ${ }^{56}$

Another important consideration in utilizing therapeutic hypothermia is the effect of cooling on drug metabolism. Phenytoin elimination in children with TBI has been shown to decrease with therapeutic hypothermia, ${ }^{57}$ posing an extended risk for drug toxicity. Based on the current evidence, maintaining normothermia is recommended in the setting of pediatric TBI (level II evidence).

\section{DIRECTIONS FOR FUTURE RESEARCH}

The evidence available to guide first line physicians when approaching a head-injured child is still found lacking in many crucial areas (Table 1). ${ }^{5-7,10,28,39,40,53,55-57}$ Understanding of age-specific variations and developing individualized strategies ${ }^{58}$ would enable the physician to apply these treatment principles in a more selective way. We eagerly await the results from ongoing trials that are studying the physiologic mechanisms in pediatric $\mathrm{TBI}^{59}$ and exploring the impact of shared decision making with parents in deciding on head $\mathrm{CT}^{60}$ As already done in adult TBI research, panels of experts in pediatric TBI have determined data elements that are essential in the various areas of TBI. ${ }^{61-64}$ These common platforms will allow for further collaborations and conduct of larger studies. ${ }^{65}$ There is a pressing need for more collaborative research in this area to inform important decisions that the ED physicians must make when managing a child with TBI.

\section{CONFLICT OF INTEREST}

No potential conflict of interest relevant to this article was reported. 


\section{ACKNOWLEDGMENTS}

The authors would like to thank Ms Peggy Fong Bih Yuh for her kind assistance in preparing the manuscript for submission.

\section{REFERENCES}

1. American College of Surgeons. Advanced trauma life support: student course manual. 9th ed. Chicago: American College of Surgeons; 2012.

2. Giza CC, Mink RB, Madikians A. Pediatric traumatic brain injury: not just little adults. Curr Opin Crit Care 2007;13:143-52.

3. Mathews JD, Forsythe AV, Brady Z, et al. Cancer risk in 680,000 people exposed to computed tomography scans in childhood or adolescence: data linkage study of 11 million Australians. BMJ 2013;346:f2360.

4. Pearce MS, Salotti JA, Little MP, et al. Radiation exposure from CT scans in childhood and subsequent risk of leukaemia and brain tumours: a retrospective cohort study. Lancet 2012;380: 499-505.

5. Dunning J, Daly JP, Lomas JP, et al. Derivation of the children's head injury algorithm for the prediction of important clinical events decision rule for head injury in children. Arch Dis Child 2006;91:885-91.

6. Kuppermann N, Holmes JF, Dayan PS, et al. Identification of children at very low risk of clinically-important brain injuries after head trauma: a prospective cohort study. Lancet 2009; 374:1160-70.

7. Osmond MH, Klassen TP, Wells GA, et al. CATCH: a clinical decision rule for the use of computed tomography in children with minor head injury. CMAJ 2010;182:341-8.

8. Easter JS, Bakes K, Dhaliwal J, Miller M, Caruso E, Haukoos JS. Comparison of PECARN, CATCH, and CHALICE rules for children with minor head injury: a prospective cohort study. Ann Emerg Med 2014;64:145-52

9. Nigrovic LE, Schunk JE, Foerster $A$, et al. The effect of observation on cranial computed tomography utilization for children after blunt head trauma. Pediatrics 2011;127:1067-73.

10. Schonfeld D, Fitz BM, Nigrovic LE. Effect of the duration of emergency department observation on computed tomography use in children with minor blunt head trauma. Ann Emerg Med 2013;62:597-603.

11. Karpas $A$, Finkelstein $M$, Reid S. Which management strategy do parents prefer for their head-injured child: immediate computed tomography scan or observation? Pediatr Emerg Care 2013;29:30-5.

12. Babl FE, Lyttle MD, Bressan $S$, et al. A prospective observa- tional study to assess the diagnostic accuracy of clinical decision rules for children presenting to emergency departments after head injuries (protocol): the Australasian Paediatric Head Injury Rules Study (APHIRST). BMC Pediatr 2014;14:148.

13. Chesnut RM, Marshall LF, Klauber MR, et al. The role of secondary brain injury in determining outcome from severe head injury. J Trauma 1993;34:216-22.

14. Hardcastle N, Benzon HA, Vavilala MS. Update on the 2012 guidelines for the management of pediatric traumatic brain injury: information for the anesthesiologist. Paediatr Anaesth 2014;24:703-10.

15. Flower 0 , Hellings $\mathrm{S}$. Sedation in traumatic brain injury. Emerg Med Int 2012;2012:637171.

16. Roberts DJ, Hall RI, Kramer $\mathrm{AH}$, Robertson $\mathrm{HL}$, Gallagher $\mathrm{CN}$, Zygun DA. Sedation for critically ill adults with severe traumatic brain injury: a systematic review of randomized controlled trials. Crit Care Med 2011;39:2743-51.

17. Bramwell KJ, Haizlip J, Pribble C, VanDerHeyden TC, Witte M. The effect of etomidate on intracranial pressure and systemic blood pressure in pediatric patients with severe traumatic brain injury. Pediatr Emerg Care 2006;22:90-3.

18. Malerba G, Romano-Girard F, Cravoisy A, et al. Risk factors of relative adrenocortical deficiency in intensive care patients needing mechanical ventilation. Intensive Care Med 2005;31: 388-92.

19. Farling PA, Johnston JR, Coppel DL. Propofol infusion for sedation of patients with head injury in intensive care: a preliminary report. Anaesthesia 1989;44:222-6.

20. Pinaud M, Lelausque JN, Chetanneau A, Fauchoux N, Menegalli $D$, Souron R. Effects of propofol on cerebral hemodynamics and metabolism in patients with brain trauma. Anesthesiology 1990;73:404-9.

21. Bray RJ. Propofol infusion syndrome in children. Paediatr Anaesth 1998;8:491-9.

22. Junttila MJ, Gonzalez M, Lizotte E, et al. Induced Brugada-type electrocardiogram, a sign for imminent malignant arrhythmias. Circulation 2008;117:1890-3.

23. Bourgoin A, Albanese J, Leone M, Sampol-Manos E, Viviand $X$, Martin C. Effects of sufentanil or ketamine administered in target-controlled infusion on the cerebral hemodynamics of severely brain-injured patients. Crit Care Med 2005;33:110913.

24. Filanovsky $Y$, Miller $P$, Kao J. Myth: ketamine should not be used as an induction agent for intubation in patients with head injury. CJEM 2010;12:154-7.

25. Bar-Joseph G, Guilburd Y, Tamir A, Guilburd JN. Effectiveness of ketamine in decreasing intracranial pressure in children 
with intracranial hypertension. J Neurosurg Pediatr 2009;4: 40-6.

26. Cohen $L$, Athaide V, Wickham ME, Doyle-Waters MM, Rose NG, Hohl CM. The effect of ketamine on intracranial and cerebral perfusion pressure and health outcomes: a systematic review. Ann Emerg Med 2015;65:43-51.

27. Curley G, Kavanagh BP, Laffey JG. Hypocapnia and the injured brain: more harm than benefit. Crit Care Med 2010;38:134859.

28. Skippen P, Seear M, Poskitt K, et al. Effect of hyperventilation on regional cerebral blood flow in head-injured children. Crit Care Med 1997;25:1402-9.

29. Curry R, Hollingworth W, Ellenbogen RG, Vavilala MS. Incidence of hypo- and hypercarbia in severe traumatic brain injury before and after 2003 pediatric guidelines. Pediatr Crit Care Med 2008;9:141-6.

30. Kochanek PM, Carney N, Adelson PD, et al. Guidelines for the acute medical management of severe traumatic brain injury in infants, children, and adolescents: second edition. Pediatr Crit Care Med 2012;13 Suppl 1:S1-82.

31. Ramaiah VK, Sharma D, Ma L, Prathep S, Hoffman NG, Vavilala MS. Admission oxygenation and ventilation parameters associated with discharge survival in severe pediatric traumatic brain injury. Childs Nerv Syst 2013;29:629-34.

32. Mendelow AD, Teasdale GM, Russell T, Flood J, Patterson J, Murray GD. Effect of mannitol on cerebral blood flow and cerebral perfusion pressure in human head injury. J Neurosurg 1985;63:43-8.

33. Misra UK, Kalita J, Ranjan P, Mandal SK. Mannitol in intracerebral hemorrhage: a randomized controlled study. J Neurol Sci 2005;234:41-5.

34. Exo J, Smith C, Smith R, Bell M. Emergency treatment options for pediatric traumatic brain injury. Ped Health 2009;3:53341.

35. Bennett TD, Statler KD, Korgenski EK, Bratton SL. Osmolar therapy in pediatric traumatic brain injury. Crit Care Med 2012;40: 208-15.

36. Samant UB 4th, Mack CD, Koepsell T, Rivara FP, Vavilala MS. Time of hypotension and discharge outcome in children with severe traumatic brain injury. J Neurotrauma 2008;25:495502.

37. Khanna S, Davis D, Peterson B, et al. Use of hypertonic saline in the treatment of severe refractory posttraumatic intracranial hypertension in pediatric traumatic brain injury. Crit Care Med 2000;28:1144-51.

38. Qureshi Al, Suarez Jl. Use of hypertonic saline solutions in treatment of cerebral edema and intracranial hypertension.
Crit Care Med 2000;28:3301-13.

39. Fisher B, Thomas D, Peterson B. Hypertonic saline lowers raised intracranial pressure in children after head trauma. J Neurosurg Anesthesiol 1992;4:4-10.

40. Simma B, Burger R, Falk M, Sacher P, Fanconi S. A prospective, randomized, and controlled study of fluid management in children with severe head injury: lactated Ringer's solution versus hypertonic saline. Crit Care Med 1998;26:1265-70.

41. Peterson B, Khanna S, Fisher B, Marshall L. Prolonged hypernatremia controls elevated intracranial pressure in head-injured pediatric patients. Crit Care Med 2000;28:1136-43.

42. Ates 0 , Ondul $S$, Onal C, et al. Post-traumatic early epilepsy in pediatric age group with emphasis on influential factors. Childs Nerv Syst 2006;22:279-84.

43. Arango Jl, Deibert CP, Brown D, Bell M, Dvorchik I, Adelson PD. Posttraumatic seizures in children with severe traumatic brain injury. Childs Nerv Syst 2012;28:1925-9.

44. Brain Trauma Foundation; American Association of Neurological Surgeons; Congress of Neurological Surgeons, et al. Guidelines for the management of severe traumatic brain injury. XIII. Antiseizure prophylaxis. J Neurotrauma 2007;24 Suppl 1:S83-6.

45. Temkin NR, Dikmen SS, Wilensky AJ, Keihm J, Chabal S, Winn HR. A randomized, double-blind study of phenytoin for the prevention of post-traumatic seizures. N Engl J Med 1990; 323:497-502.

46. Young KD, Okada PJ, Sokolove PE, et al. A randomized, double-blinded, placebo-controlled trial of phenytoin for the prevention of early posttraumatic seizures in children with moderate to severe blunt head injury. Ann Emerg Med 2004;43: 435-46.

47. Liesemer K, Bratton SL, Zebrack CM, Brockmeyer D, Statler KD. Early post-traumatic seizures in moderate to severe pediatric traumatic brain injury: rates, risk factors, and clinical features. J Neurotrauma 2011;28:755-62.

48. Klein P, Herr D, Pearl PL, et al. Results of phase 2 safety and feasibility study of treatment with levetiracetam for prevention of posttraumatic epilepsy. Arch Neurol 2012;69:1290-5.

49. Pearl PL, McCarter R, McGavin $C L$, et al. Results of phase II levetiracetam trial following acute head injury in children at risk for posttraumatic epilepsy. Epilepsia 2013;54:e135-7.

50. Li H, Lu G, Shi W, Zheng S. Protective effect of moderate hypothermia on severe traumatic brain injury in children. J Neurotrauma 2009;26:1905-9.

51. Biswas AK, Bruce DA, Sklar FH, Bokovoy JL, Sommerauer JF. Treatment of acute traumatic brain injury in children with moderate hypothermia improves intracranial hypertension. 
Crit Care Med 2002;30:2742-51.

52. Ma $C$, He $X$, Wang $L$, et al. Is therapeutic hypothermia beneficial for pediatric patients with traumatic brain injury? A meta-analysis. Childs Nerv Syst 2013;29:979-84.

53. Hutchison JS, Ward RE, Lacroix J, et al. Hypothermia therapy after traumatic brain injury in children. N Engl J Med 2008; 358:2447-56.

54. Adelson PD, Ragheb J, Kanev P, et al. Phase II clinical trial of moderate hypothermia after severe traumatic brain injury in children. Neurosurgery 2005;56:740-54.

55. Adelson PD, Wisniewski SR, Beca J, et al. Comparison of hypothermia and normothermia after severe traumatic brain injury in children (Cool Kids): a phase 3, randomised controlled trial. Lancet Neurol 2013;12:546-53.

56. Hutchison JS, Guerguerian AM. Cooling of children with severe traumatic brain injury. Lancet Neurol 2013;12:527-9.

57. Empey PE, de Mendizabal NV, Bell MJ, et al. Therapeutic hypothermia decreases phenytoin elimination in children with traumatic brain injury. Crit Care Med 2013;41:2379-87.

58. Scaife ER, Statler KD. Traumatic brain injury: preferred methods and targets for resuscitation. Curr Opin Pediatr 2010;22: 339-45.

59. Duke University. Physiologic mechanisms in pediatric traumatic brain injury [Internet]. Bethesda: ClinicalTrials.gov; 2014 [cit- ed 2014 Aug 25]. Available from: http://clinicaltrials.gov/ct2/ show/NCT01763892.

60. Mayo Clinic. Shared decision making in parents of children with head trauma: head CT choice [Internet]. Bethesda: ClinicalTrials.gov; 2014 [cited 2014 Aug 25]. Available from: http: //clinicaltrials.gov/ct2/show/NCT02063087.

61. Adelson PD, Pineda J, Bell MJ, et al. Common data elements for pediatric traumatic brain injury: recommendations from the working group on demographics and clinical assessment. J Neurotrauma 2012;29:639-53.

62. Berger RP, Beers SR, Papa L, Bell M; Pediatric TBI CDE Biospecimens and Biomarkers Workgroup. Common data elements for pediatric traumatic brain injury: recommendations from the biospecimens and biomarkers workgroup. J Neurotrauma 2012; 29:672-7.

63. Duhaime AC, Holshouser B, Hunter JV, Tong K. Common data elements for neuroimaging of traumatic brain injury: pediatric considerations. J Neurotrauma 2012;29:629-33.

64. McCauley SR, Wilde EA, Anderson VA, et al. Recommendations for the use of common outcome measures in pediatric traumatic brain injury research. J Neurotrauma 2012;29:678-705.

65. Bell MJ, Kochanek PM. Pediatric traumatic brain injury in 2012: the year with new guidelines and common data elements. Crit Care Clin 2013;29:223-38. 